\title{
Online Social Networking and its Perceived Life Satisfaction among Sri Lankan Medical Students
}

\author{
De Zoysa, P. ${ }^{1}$, Wickrama, $T^{2}{ }^{2}$, Wickramasuriya, $T^{3}$
}

\begin{abstract}
Objective: Studies on online social networking and its impact on life satisfaction of young adults are scant in Sri Lanka. This study aspired to fill this gap by exploring selected aspects of life satisfaction and online social networking.

Methods: A cross sectional study was carried out at a Faculty of Medicine of a Sri Lankan University. A total of 459 medical students from first to fourth years of study participated. Four self-administered scales on (i) Use of Internet Social Networking; (ii) Meeting Friends; (iii) Social Support; and (iv) Life Satisfaction were adapted from existing literature and used.

Results: A majority of medical students uses Facebook while a less number uses online chat rooms. Even with greater online social networking, there were more actual meetings with friends; these meetings were positively associated with perceived social support from friends; and these meetings had an impact on students' perceived life satisfaction.

Conclusions: The study indicated that online social networking has beneficial effects on medical students, in particular in the area of perceived life satisfaction. However, these benefits should be weighed alongside the detriment to privacy and medical professionalism.
\end{abstract}

Key words: Medical education; Professionalism

\section{Introduction}

Social networking sites (SNS) are places for individuals to openly express themselves, articulate their thoughts, and communicate with their social network (Ellison et al., 2006). Facebook (FB) is one such site and is reported to be the most preferred SNS among university students (Educause, 2012). Some opine that social online communication (OC) hinders wellbeing because it displaces time that could be spent with actual friends (Nie et al., 2002).

${ }^{1}$ Professor in Clinical Psychology, Department of Psychological Medicine, Faculty of Medicine, University of Colombo, Sri Lanka.

${ }^{2}$ Assistant Professor, Department of Human Development and Family Studies, Auburn University, Auburn, USA

${ }^{3}$ Research Assistant, Department of Psychological Medicine, Faculty of Medicine, University of Colombo, Sri Lanka

Corresponding Author:

Dr. Piyanjali de Zoysa,

Professor in Clinical Psychology, Department of

Psychological Medicine, Faculty of Medicine,

University of Colombo, Sri Lanka

Email:ptdz@s/tnet.lk
Hence, online relationships are seen by some as superficial and lacking in affection and commitment. It is considered to reduce the quality of existing friendships and thereby wellbeing (Nie et al., 2002), and academic performance too has been shown to be negatively impacted by spending time on SNS (Junco, 2012). Thus, educators have expressed concern about the amount of time students are involved in such activities.

Contrary to the above, other studies have indicated that OC may enhance the quality of existing friendships and consequent well-being. They argue that much of the time spent on OC is actually used to keep up existing friendships (Gross, 2004) rather than to connect with superficial contacts. Indeed, there is evidence to show that OC is positively related to time spent with existing friends (Kraut et al., 1998), to the closeness of existing friendships (Valkenburg \& Peter, 2007), to well-being (Wang \& Wang, 2011), to improving social integration (Junco, 2012), opportunities for peer-to-peer learning (Junco, 2012), and for improving technological and communication skills valued in today's workplace (Junco, 2012). As a qualifier however, the association 
of SNS with academic and career success is seen among those who use sites such as FB to share information rather than simply for socializing purposes (Junco, 2012).

Online social networking sites such as FB require a person to create a public profile of oneself. Pictures or comments in the profile may remain unchanged even after the user's attitudes and behaviours associated with them have changed (Cain, 2008). Medical students are expected to demonstrate accountability to patients, society and the profession, and medical educators are challenged to teach their students such professionalism (Wear \& Aultman, 2006). Medical students' online profiles may include information about political and religious views, sexual orientation, relationship status, photographs, and information such as address, phone number and daily schedule (Ferdrig et al., 2008). This publicly available content is a reflection on their professionalism. In fact, unprofessionalism in these SNS may exacerbate the increasingly negative sentiments that the general public seem to have with regards to the medical community (Ferdrig et al., 2008).

Hence, worldwide, several universities have informed students of the potential ramifications of their online activities (Read, 2006). However, issues of student rights and the difficulty in regulating student activity on the internet have made it difficult for universities to monitor SNS use (Kornblum \& Marklein, 2006).

Studies on the impact of social networking among Sri Lankan university students, including medical students, are scarce. Results of such studies would be useful for university teachers and administrators when developing guidelines/student-advice, if any, in relation to online networking activities. Therefore, the present study aimed to bridge this gap by investigating the impact of social networking on selected aspects of perceived life satisfaction among medical students. In order to this, our study first explored the amount of time medical students spent on FB and in online chat rooms. Second, it explored if online social networking was positively associated with meeting friends (Kraut et al., 1998). The study further explored if meeting friends was positively associated with receiving social support from friends (Valkenburg \& Peter, 2007). Finally, the study investigated if greater social support was positively associated with life satisfaction. Moreover, the present study investigated if the association between meeting friends and life satisfaction was mediated by social support from friends (Figure 1). The present study selected the construct of meeting friends as a factor associated with life satisfaction.

\section{Figure 1: Theoretical Model. The Direct, Indirect, and Mediational Effect in the Association between Internet Social Networking and selected aspects of Life Satisfaction}

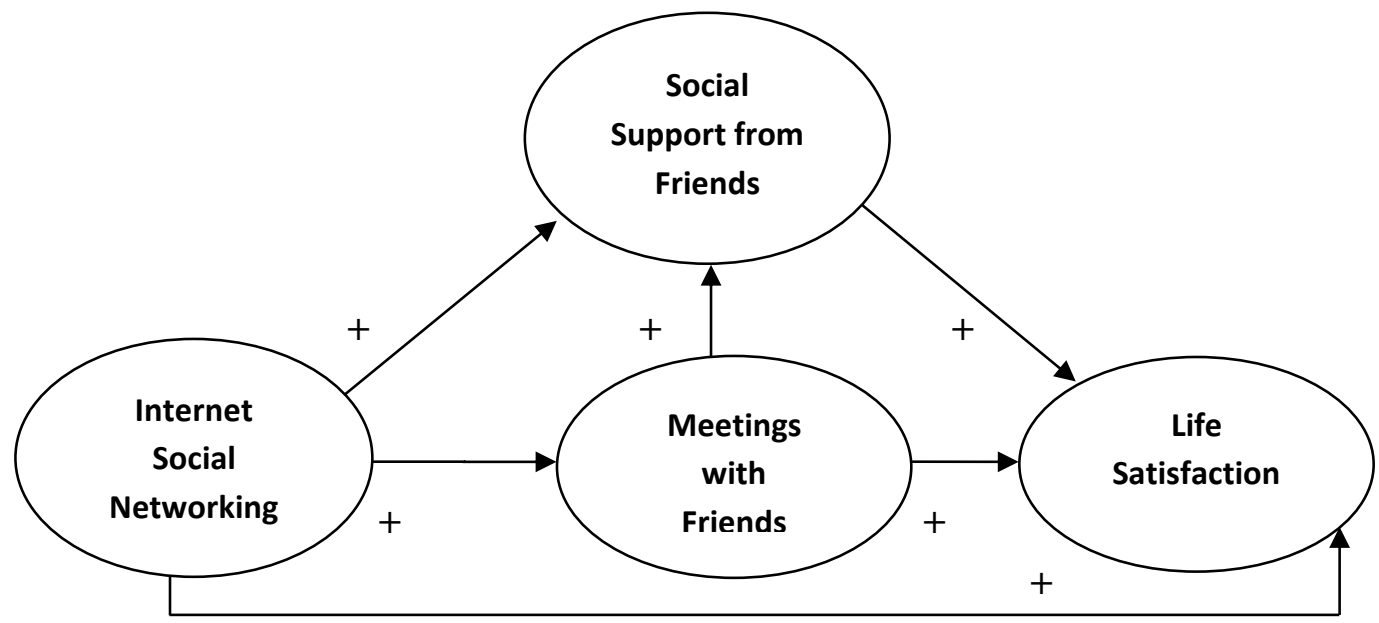

\section{Methodology}

\section{Sample}

The study was conducted among 459 medical students at a Sri Lankan university. Ages ranged from 17 to 25 years (mean=21,
$\mathrm{SD}=1.97)$ and $53 \%$ were women. $8 \%$ were in the first year of university, $23 \%$ were secondyear students, 35\% were third-year students, and $34 \%$ were in the fourth-year. Fifth-year students did not participate as they could not be contacted. Out of the sample, $66 \%$ were, single, $32 \%$ were in a relationship but unmarried, while 
$2 \%$ were married. Nearly $70 \%$ originated from urban areas while nearly $90 \%$ resided in urban areas.

\section{Procedure}

The study was approved by the Ethics Review Committee of the Faculty of Medicine, Colombo. At a scheduled lecture period, students who were present at that time were informed about the study and were invited to participate. They were informed that their personal details would be kept confidential, that the survey is not a required part of their university curriculum, and that they could withdraw from the study at any time. The students were asked to complete the measures during the remaining lecture time.

\section{Measures}

Four self-administered scales were used:

Life Satisfaction measure consisted of five items anchored on a scale from 1 (strongly disagree) to 7 (strongly agree) (e.g. "In most ways my life is close to my ideal"). This measure was adapted from existing scales on the subject (Diener, 1985).

Social Support measure consisted of seven items regarding students' perceived social support from their friends once they met them face to face (De Zoysa, 2006) (e.g. "Do these friends help you when you are unhappy?"). These items anchored on a scale from 1 (never) to 5 (always).

Meeting Friends Three items were asked regarding the frequency students met with friends (e.g. "How often do you meet with one or more of these friends?"). These items were scored from 1 (never) to 9 (several times a day). This scale was adapted from an existing scale on the subject (Valkenburg \& Peter, 2007).

Internet Social Networking Five questions were asked concerning Facebook use and the same questions concerning online chat use [e.g. "On weekdays (Monday to and including Friday), how many days do you usually use FB?]. This scale was adapted from an existing scale on the subject (Valkenburg \& Peter, 2007).

The Life Satisfaction scale (Diener, 1985) and the Social Support scale (De Zoysa, 2006) have both shown good psychometricproperties of validity and reliability. The original scales from which the Meeting Friends scale (Valkenburg \&
Peter, 2007) and the Internet Social Networking scale (Valkenburg \& Peter, 2007) were adapted, too have reported good psychometric properties.

\section{Analysis}

Structural Equation Modeling using AMOS 16 software was the principal analytical strategy. The latent constructs in the structural equation models included Internet Social Networking, Meetings with Friends, Social Support from Friends, and Life Satisfaction. The measures/indicators of these latent constructs were continuous variables. Rather than relying on any single goodness-of-fit index, a range of indices to evaluate the fit of the model (e.g. chisquare statistics) was used. The Normed Fit Index (NFI) and the Root Mean Squared Error of Approximation (RMSEA) were also used to evaluate the study models. Missing values were managed using the FIML.

\section{Results}

Results revealed that $72 \%$ of students have a profile on Facebook, and, on average, they spend 1.4 hours on it during the working days (Monday to Friday), and 1.6 and 1.5 . hours on it on Saturday and Sunday respectively. With respect to public chat rooms, $19 \%$ of students chat on online chat rooms, and on average they do so for 1 hour on weekdays and 1.2 hours each on Saturday and Sunday, respectively.

Meetings with Friends was also positively associated with Social Support from Friends $(\beta=.48, p<.001)$, indicating greater perceived social support from them. In addition, Meetings with Friends directly affected Life Satisfaction $(\beta=.14, \quad p<.05)$, with greater meetings with friends associated with an increased perceived sense of life satisfaction. Social Support from Friends was also positively associated with Life Satisfaction $(\beta=.25, p<.001)$, ( figure 2.).

With greater perceived support from friends, participants felt greater life satisfaction. However, the significant direct effect of Meetings with Friends on Life Satisfaction was fully mediated by Social Support from Friends. This indicates that the perceived social support from friends is a more proximal cause of life satisfaction than meetings with friends. While not illustrated in Figure 2, testing the direct effect of Internet Social Networking on Social Support from Friends and the direct effect of Internet Social Networking on Life Satisfaction yielded that neither was significant $(\beta=.08$, $p>.05$ and $\beta=-.00, p>.05$, respectively). 
Figure 2: Significant linking and mediating mechanisms between internet social networking and selected aspects of life satisfaction (Standardized Coefficients)

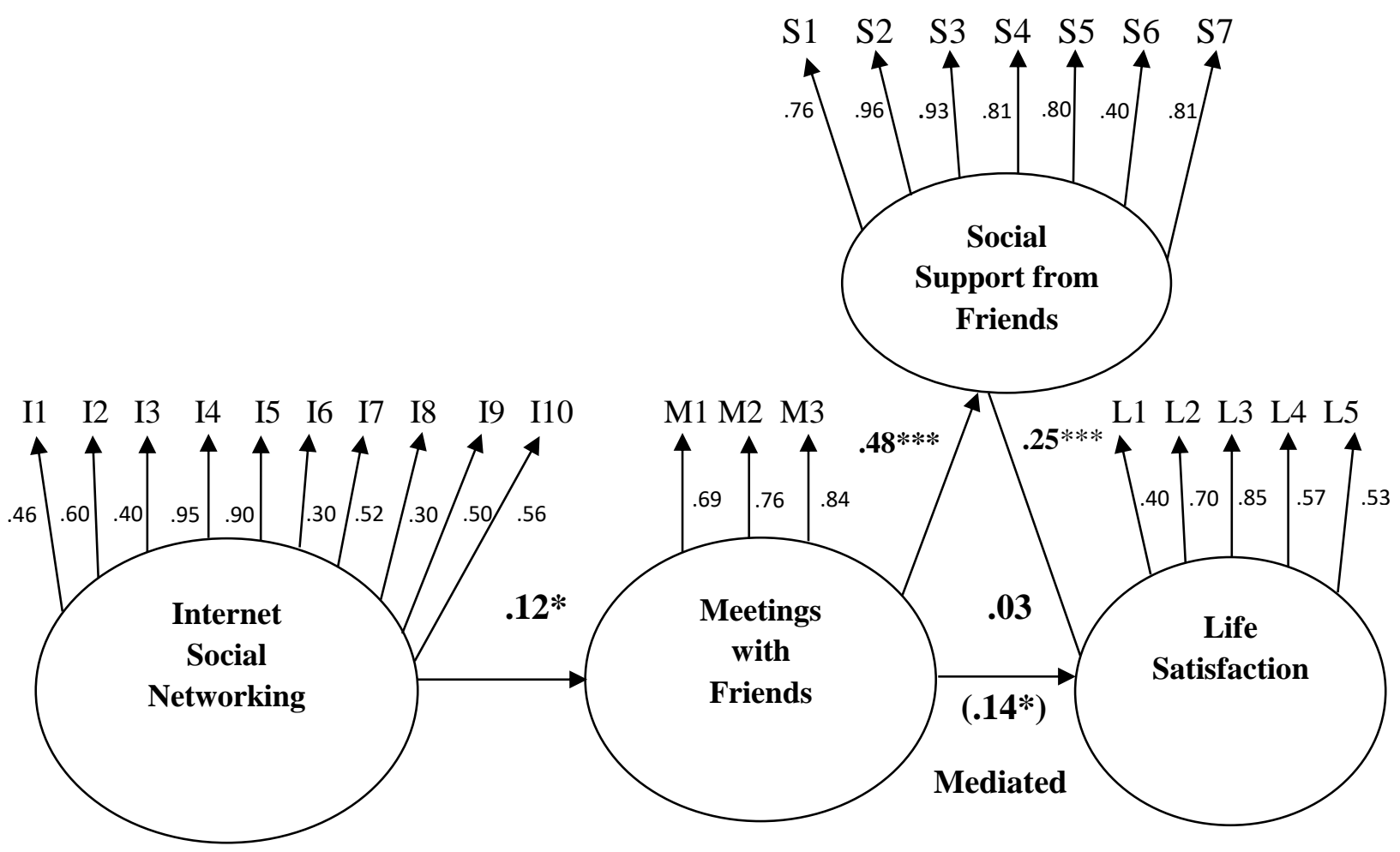

Model Fit: $\chi 2 / d f=2.63, R M S E A=.06, C F I=.91, N=459,{ }^{* * *} P<.001,{ }^{* *} P<.01,{ }^{*} P<.05$

\section{Discussion}

This study revealed that Sri Lankan medical students frequently use Facebook as a means for social networking, whilst there was less use of online chat rooms. Facebook use maybe more favoured because of its user-friendliness and superior social networking opportunities. Additionally, the authors opine that in traditional societies such as Sri Lanka, FB maybe more socially accepted because of its 'open and visible' and 'non-nefarious' nature. In fact, online chat rooms continue to be viewed with some suspicion by most Sri Lankans as these sites are considered to be not fully 'aboveboard'.

The study shows that there is a positive association between internet social networking and meetings with friends. This means that greater the online social networking, the greater the tendency for people to have actual meetings with friends. Hence, time spent on the internet is used to maintain relationships within the existing social network (Gross, 2004) which may then lead to actual face to face meetings with these online friends. These findings refute the view that $O C$ adversely affects the maintenance of existing social networks and that it displaces time that could be spent with existing friends (Nie et al., 2002). It is often observed that friends in Sri Lanka lose touch with each other, once the cause for their physical proximity (such as being in school together) ceases. However, with tools such as FB, young people may have a chance to better keep in touch with their friends, virtually, and, with the possibility of actual meetings too. Hence, with the use of online mechanisms, the possibilities of face to face meeting is increased, giving youth a chance to increase their social support and overall life satisfaction.

The present study also explored if meeting friends was positively associated with receiving social support. The findings revealed that indeed, with greater meetings with friends, participants perceived greater social support from them. This corresponds to similar research findings (Valkenburg \& Peter, 2007). Indeed, it is known that the more opportunity there is to meet another, the greater the tendency to find out commonalities between one another, leading to a deepening of friendship. Hence, the meetings with friends resulting from FB usage appear to strengthen these friendships, which in turn leads to a greater sense of social support.

The present study further explored if greater social support from friends increased participants' perceived sense of life satisfaction. In fact, in line with previous 
research (Wang \& Wang, 2011), this study too revealed so. The study further investigated if the association between meeting friends and life satisfaction was mediated by social support from friends. The results revealed that this positive and significant direct effect of meetings on life satisfaction is fully mediated by perceived social support from friends. This indicates a more proximal and powerful impact of social support from friends on life satisfaction than simply meeting with friends.

In this age of $\mathrm{OC}$, there is a blurring of the interface between work and personal time. Social networking websites are popular among young pre-professionals, and allow those such as medical students to communicate and share information with peers and others via online profiles. The present study indicates that these online communication activities have a host of benefits for medical students, culminating in an increase in their perceived life satisfaction. However, another side of this online communication also needs to be acknowledged. Medical students, with their sense of medical professionalism just beginning to develop, may not understand that their publicly available content reflects their professionalism. Unknowingly, medical educators and even patients may have access to their content online, not without consequences. Education in professionalism needs to address these activities, however, without forgoing the emotional and social benefits of such online social networking.

The present study was conducted at one of the medical faculties in Sri Lanka. Students from this particular institution are mainly from urban communities. Hence, their pattern of online social networking and its subsequent universities and young adults, in general, in Sri Lanka. Future research would need to have a more representative sample of Sri Lankan youth in order to ensure a wider generalizability of results. Further, this study explored only certain aspects of life satisfaction. There are several others which were not studied, primarily due to time and economic constraints. Further studies on this area could explore these aspects.

\section{References}

Cain, J. (2008) Online social networking issues within academia and pharmacy education, American Journal of Pharmacy Education, 72, p.10.

De Zoysa, P. (2006) Parental use of physical force towards school children in the Colombo district: Prevalence, psychosocial correlates \& psychological consequences, Doctoral dissertation, University of Colombo, Sri Lanka, pp. 160-191.

Diener, E., Emmons, R.A., Larsen, R.J. \& Griffin, S. (1985) The satisfaction of life scale, The Journal of Personality Assessment, 49, pp. 71-75.

Educause, (2012) 7 things you should know about Facebook, Educause Learning Initiative [Online] Available at: http://www.educause.edu/ir/library /pdf/ELI7017.pdf [Accessed 18th July 2012].

Ellison, N., Steinfeld, C. \& Lampe, C. (2006) Spatially bounded online social networks and social capital: The role of Facebook, Paper presented at the Annual Conference of the International Communication Association; June 19-23; Dresden, Germany.

Ferdig, R.E., Dawson, K., Black, E.W., Paradise Black, N.M. \& Thompson, A. L. (2008) Medical students' and residents use of online social networking tools: Implications for teaching professionalism for medical education, First Monday, 13, 9.

Gross, E.F. (2004) Adolescent Internet use: What we expect, what teens report, Journal of Applied Developmental Psychology, 25, pp. 633-649.

Junco, R. (2012) Too much face and not enough books: The relationship between multiple indices of Facebook use and academic performance, Computers in Human Behaviour, 28, pp. 11871198.

Kornblum, J, \& Marklein, M.B. (2006) What you say online could haunt you, USA Today, March 9.

Kraut, R., Patterson, M., Lundmark, V., Kiesler, S., Mukopadhyay, T., \& Scherlis W. (1998) Internet paradox: A social technology that reduces social involvement and psychological well-being? American Psychologist, 53, pp. 1017-1031.

Nie, N.H., Hillygus, D.S., \& Erbring, L. (2002) Internet use, interpersonal relations, and sociability: A time diary study, In B. Wellman \& C. Haythornthwaite (Eds.), The Internet in Everyday Life, Oxford: Blackwell.

Read, B. (2006) Think before you share, Chronicles of Higher Education, 52, pp. A38-A41.

Valkenburg, P.M., \& Peter, J. (2007) Online communication and adolescent well-being: Testing the stimulation versus the displacement hypothesis, Journal of Computer-Mediated Communication, 12, pp. 2.

Wang, J., \& Wang, H. (2011) The predictive effects of online communication on well-being among Chinese adolescents, Psychology, 2, pp. 359-362.

Wear, D. \& Aultman, J.M. (2006) Professionalism in medicine: Critical perspectives, New York: Springer. 